\title{
Real-time PCR detection of the Hhal tandem DNA repeat in pre- and post-patent Brugia malayi infections: a study in Indonesian transmigrants
}

\author{
Anna Albers ${ }^{1}$, Erliyani Sartono ${ }^{2}$, Sitti Wahyuni ${ }^{3}$, Maria Yazdanbakhsh² ${ }^{2}$ Rick M Maizels ${ }^{4}$, Ute Klarmann-Schulz ${ }^{1,5}$,
} Kenneth Pfarr $^{1 *}$ and Achim Hoerauf ${ }^{1}$

\begin{abstract}
Background: Lymphatic filariasis caused by Wuchereria bancrofti or Brugia spp. is a public health problem in developing countries. To monitor bancroftian filariasis infections, Circulating Filarial Antigen (CFA) test is commonly used, but for brugian infections only microfilariae (Mf) microscopy and indirect lgG4 antibody analyses are available. Improved diagnostics for detecting latent infections are required.

Methods: An optimized real-time PCR targeting the brugian Hhal repeat was validated with plasma from microfilariae negative Mongolian gerbils (jirds) infected with B. malayi. Plasma samples from microfilaremic patients infected with B. malayi or W. bancrofti were used as positive and negative controls, respectively. PCR results of plasma samples from a transmigrant population in a B. malayi endemic area were compared to those of life-long residents in the same endemic area; and to lgG4 serology results from the same population. To discriminate between active infections and larval exposure a threshold was determined by correlation and Receiver-Operating Characteristics (ROC) curve analyses.

Results: The PCR detected Hhal in pre-patent ( 56 dpi) B. malayi infected jirds and B. malayi Mf-positive patients from Central Sulawesi, Indonesia. Hhal was also detected in 9/9 elephantiasis patients. In South Sulawesi $87.4 \%$ of the transmigrants and life-long residents (94\% Mf-negative) were Hhal PCR positive. Based on ROC-curve analysis a threshold for active infections was set to $>53$ Hhal copies/ $\mu$ l (AUC: 0.854).

Conclusions: The results demonstrate that the Hhal PCR detects brugian infections with greater sensitivity than the IgG4 test, most notably in Mf-negative patients (i.e. pre-patent or latent infections).
\end{abstract}

Keywords: Brugia malayi, amicrofilaremic, real-time PCR, Hhal, pre-patent, detection

\section{Background}

Lymphatic filariasis (LF) affects approximately 120 million people in 73 endemic countries [1]. Wuchereria bancrofti accounts for $\sim 90 \%$ of LF cases, while Brugia malayi and B. timori infections account for the remainder [2]. Approximately 15 million people with LF live in Southeast Asia [3]. Indonesia is part of the Global Programme to Eliminate Lymphatic Filariasis (GPELF), a multi-national initiative that aims to eliminate disease transmission by 2020. GPELF employs mass drug administration (MDA) to reduce filarial infection rates below those required for

\footnotetext{
* Correspondence: pfarr@microbiology-bonn.de

'Institute of Medical Microbiology, Immunology and Parasitology, University Hospital of Bonn, Sigmund-Freud-Str. 25, D-53105 Bonn, Germany Full list of author information is available at the end of the article
}

sustained transmission with the goal of permanently eliminating LF caused by $B$. malayi and $W$. bancrofti $[4,5]$. GPELF relies on diagnostic tests to map LF-endemic areas and to monitor the impact of MDA. Thick blood smear examination is used for routine diagnosis and prevalence studies in Brugia endemic countries [6,7]. This method detects microfilariae (Mf) in the peripheral blood but, due to the nocturnal periodicity of microfilaremia in these areas, requires night-time collection, which is unpopular with the local population. Furthermore, this method is relatively insensitive [8].

In bancroftian filariasis, circulating filarial antigen (CFA) can be measured in plasma by a rapid card test $[9,10]$ or enzyme-linked immunosorbent assay (ELISA). CFA determination revealed that approximately twice as many 
individuals are CFA-positive (CFA+) than are microfilaremic, thus a proportion of Mf-negative people equal to the Mf-positive people harbors cryptic infections [11]. Visualizing adult worms by ultrasonography (USG) is also possible in W. bancrofti infections which is helpful for monitoring adult worm viability, e.g. after macrofilaricidal treatment [6].

However, for brugian LF, a specific antigen test like CFA does not exist and USG is unable to detect cryptic infections [12]. Exposure to brugian parasites is determined by brugian specific IgG4 serology using recombinant antigens in ELISAs [13,14] or rapid-format assays (BmR1-Brugia Rapid [15] and CELISA [16]) with up to 95\% sensitivity in Mf-positive samples. The ELISA format using soluble worm antigen (SWA) was shown to be more sensitive compared to the rapid-format which could be due to the mixture of antigens used in the ELISA. However, IgG4 serology has limited use in crosssectional surveys since it does not differentiate latent or occult infections from exposure to infective larvae. With less sensitivity it is also cross-reactive with $W$. bancrofti related antibodies and therefore has limited use in coendemic areas.

Real-time PCR is a powerful tool for high-throughput detection of parasite DNA and is increasingly replacing conventional-PCR and microscopy for diagnosis of several parasitic infections $[17,18]$. Using a real-time PCR assay targeting the $B$. malayi HhaI repeat, a sensitive and specific detection of nocturnally periodic $B$. malayi DNA in day blood samples was possible including 33\% of Mf-negative samples in a highly endemic area [19]. Recently a multiplex real-time PCR assay for the $B$. malayi HhaI and W. bancrofti Long DNA Repeat was established for use in co-endemic areas [20]. This once more showed that real-time PCR assays provide a significant cost and labor saving procedure for disease monitoring efforts in endemic locations as part of the Global Progamme for the Elimination of Lymphatic Filariasis (GPELF) [20].

We evaluated the usefulness of the B. malayi HhaI PCR as a diagnostic test, especially focusing on pre-patent, latent (Mf-negative) and occult infections (seen after continued use of antifilarial drugs, i.e. post-patent), analyzing an Indonesian transmigrant population, previously analyzed for B. malayi infection using both IgG4 based tests $[21,22]$. Most studies on the dynamics of filarial infection have been carried out in populations that are lifelong residents of endemic areas. In such situations, the history of exposure to parasites is hard to determine and correlate with different diagnostic approaches. This is only possible when a naive population becomes exposed to filarial infection abruptly. In Indonesia, a governmental transmigration program in the 1990's relocated groups of people from the overcrowded islands of
Java and Bali to under-populated areas on remote islands, which are often endemic for a multiplicity of infections. This transmigration policy provided a unique situation to study the development of infection in individuals with a known and equal length of exposure to infections. We present new results concerning the dynamics of brugian infection in a population with a known time of residence in an endemic area using a modified qPCR for $B$. malayi HhaI that was validated using a novel cohort of Mf-negative samples.

\section{Methods}

\section{Ethics statement}

Human participants: This study used archived material from a previous project that was reviewed and approved by the ethics committee of the Medical Faculty Hasanuddin University, Makassar, South Sulawesi, Indonesia [22]. In co-operation with the medical doctors and health workers of the local District Health Centre and the head of each transmigration unit or village, all residents were informed about the study and invited to participate. Written informed consent was obtained from all study participants or parents of children and juveniles before parasitological studies and blood taking in accordance with the guidelines of the Indonesian Department of Health and Human Services.

Plasma from uninfected European controls or Toxoplasma spp. and Dirofilaria repens infected patients was obtained from blood bank volunteers after informed consent was given. Use of the plasma for diagnosis by PCR and other methods was approved by the Ethics Committee of the University Hospital of Bonn.

The use of plasma from Ghanaian volunteers infected with other parasites (W. bancrofti, Schistosoma spp. and Strongyloides stercoralis) was approved by the Committee on Human Research Publication and Ethics at the University of Science and Technology in Kumasi, Ghana and by the Ethics Committee of the University Hospital of Bonn.

Use of animals: All animal protocols were approved by the University of Edinburgh Ethical Review Committee (Certificate of Designation PCD 60/2605) and submitted to the UK Home Office which issued Project Licence PPL60/ 3453 for animal studies in the investigator's laboratory. UK Home Office guidelines to minimize animal suffering were adhered to at all times.

\section{Participants}

Plasma from B. malayi infected patients from Indonesia were from a larger cross-sectional study between 19901996 conducted in Budong-budong [21,22], a district of Mamuju Regency in South Sulawesi, Indonesia, endemic for periodic nocturnal B. malayi [23]. A transmigrant population had travelled to their new homesteads in groups 
coming from the same village or region in Bali or certain Lesser Sunda islands as part of the government-sponsored relocation program. Transmigrants from areas where filariasis is endemic (South Sulawesi and other Lesser Sunda islands) were excluded from the analysis. A total number of 247 transmigrants and 133 life-long residents (LLR) were enrolled in the study. For PCR analysis, 334 plasma samples were available for DNA extraction (Additional file 1).

\section{Detection of B. malayi infection}

Venous blood samples $(10 \mathrm{ml})$ were collected between 20:00-24:00 as described [22]. EDTA was added to the tubes to a final concentration of $0.05 \mathrm{M}$. After centrifugation, collected plasma was stored at $-20^{\circ} \mathrm{C}$ until shipment to Europe and then stored at $-70^{\circ} \mathrm{C}$ until use. Parasitological examination and detection of filarial specific IgG4 antibodies using BmR1 dipstick assay (Brugia Rapid ${ }^{\mathrm{TM}}$ ) were done in 2004 as previously described [21,22].

\section{DNA extraction and PCR}

DNA was extracted from $100 \mu$ l plasma with a QIAcube ${ }^{\circledast}$ (Qiagen, Hilden, Germany) using the QIAamp DNA Blood Mini Kit according to the blood and body fluid protocol. DNA was eluted in $100 \mu \mathrm{l}$ AE-Buffer.

The PCR assay used a QuantiTect ${ }^{\oplus}$ custom assay with primers and minor groove binding probe (QuantiProbe ${ }^{\oplus}$, Qiagen) to detect $120 \mathrm{bp}$ of the Brugia HhaI repeat (Additional file 2) [19]. Target sequence copy numbers were calculated from the $C_{t}$ values using an external standard curve generated with an HhaI plasmid dilution series that had $100 \%$ detection in samples with $>200$ copies/ $\mu$ land $80 \%$ in samples with 20 copies/ $\mu$ l.

Samples containing very low amounts of DNA and negative for HhaI were measured in a second PCR assay using the QuantiTect ${ }^{\oplus}$ Virus NR Kit. The modified master mix allows the sample DNA to make up 50\% of the PCR reaction and resulted in an improved detection limit of 2 HhaI copies/ $\mu$ l (Additional file 2). A test for inhibitors in the DNA samples was done with a reference plasmid of murine IFN- $\gamma$ (Additional file 2). An internal PCR control detected the human $\beta$-actin gene (Additional file 2).

\section{DNA extraction from plasma of $B$. malayi infected jirds}

Male adult jirds (Meriones unguiculatus) were bred and housed according to Home Office guidelines, United Kingdom. Jirds with a patent $B$. malayi infection were used as a source of venous blood during the pre-patent infection. Blood was collected by tail bleed from jirds on day 56 post infection with $B$. malayi. DNA was extracted from $100 \mu \mathrm{l}$ of plasma using the QIAamp ${ }^{\circ}$ DNA Mini Kit, eluted in $50 \mu \mathrm{l}$ and quantified with the QuantiTect ${ }^{\oplus}$ Virus NR Kit using $2 \mu \mathrm{l}$ or $10 \mu \mathrm{l}$ sample DNA per reaction.
DNA extraction from plasma used as negative controls The specificity of the HhaI PCR assay was tested using plasma samples collected from volunteers after informed consent and extracted as above from the following: $10 \mathrm{~W}$. bancrofti patients, 15 patients with other parasitic infections (Toxocara spp., Schistosoma spp., Strongyloides stercoralis, Dirofilaria repens or W. bancrofti) and 10 European blood donors without history of parasitic infection.

\section{Determination of threshold of active infections by real- time PCR}

A threshold limit of HhaI copy numbers was determined to differentiate most-likely "active" infections (i.e. infections with live adult worms) from simple exposure to infective larvae. For this the Mf loads of Mf-positive (Central Sulawesi and South Sulawesi transmigrants, $n=49)$ and LE patients (Central Sulawesi, $n=9$ ) were correlated to HhaI copies/ $\mu$ l and the Y-intercept was calculated by linear regression. To verify the results, further analysis was done by a Receiver Operating Characteristics (ROC) curve analysis using a binormal mixture model [24,25]. Individual samples were scored positive with active infection (Mf-positive, LE $\mathrm{n}=58$ ) or negative with possible exposure to infective or fourth-stage larvae (L3-L4) $(n=50$, transmigrant samples from the $\leq 1$ month and 2-4 months group, since L3 to adult development requires $\sim 8$ months). The Area Under the Curve (AUC) for the ROC-curve was calculated to measure the discriminatory power of the PCR assay [26]. A table of possible thresholds with true- and false-positive rates (\%) was calculated from the coordinates of the ROC curve.

\section{Statistical methods}

PASW 18.0 (IBM ${ }^{\oplus}$, Somers NY, USA) was used to test the comparison of two binary variables with the Fisher's exact test, to correlate two continuous parameters using Spearman's rank test and to determine a threshold copy number by ROC-curve analysis. The ROC-curve procedure is a useful tool to evaluate the performance of classification schemes that categorize samples into one of two groups (i.e. HhaI copy numbers of Mf positive (infected) vs. HhaI copy numbers of Mf negative (exposed but uninfected)). The further the curve lies above the reference line, the more accurate the test (AUC). The table with curve coordinates reports the sensitivity (true positive rate) and the 1-specificity (false positive rate) for every possible cutoff. A cutoff of 0 is equivalent to assuming that everyone is positive, the highest cutoff assumes that everyone is negative. Both extremes are unlikely, the balance of sensitivity and 1-specificity is needed to select a cutoff.

The Cochran-Armitage test for trend was calculated with SAS 9.2 (SAS, Cary, NC, USA) to compare the trend of HhaI copy numbers between the 1-3 year and the 4-6 year residents. 


\section{Results}

To establish a method for detecting cryptic (pre-patent or latent) B. malayi infections, real-time PCR for HhaI was used to measure parasite DNA in plasma samples. Using $2 \mu \mathrm{l}$ of a HhaI plasmid DNA dilution series and the Quantitect ${ }^{\circ}$ Probe master mix, 100\% (5/5) of the samples with 200 copies/ $\mu$ l were detected $\left(C_{t} 30.5-31\right)$. The reaction detected as few as 2 copies/ $\mu \mathrm{l}$ in $50 \%(5 / 10)$ of the samples $\left(C_{t} 36.5-37\right)$. A detection rate of $80 \%(4 / 5)$ was achieved for 20 copies/ $\mu \mathrm{l}$ and set as the PCR detection limit $\left(C_{t}\right.$ 34.5-35). The reaction efficiency was $\geq 85 \%$ (Additional file 3A). Negative controls did not result in a signal.

Samples with low DNA concentrations could lead to false negatives when only using $2 \mu \mathrm{l}$ of sample DNA. To increase the sample volume to a maximum of $10 \mu \mathrm{l}$, a second PCR using the QuantiTect ${ }^{\circ}$ Virus NR Kit was developed. Using $10 \mu \mathrm{l}$ of the 2 copies/ $\mu$ l plasmid dilution, the reaction efficiency was $100 \%$ and detected $100 \%$ of the samples (5/5; $\mathrm{C}_{\mathrm{t}} 33-34$; Additional file 3B).

To validate the HhaI PCR assay used for detection of B. malayi infection in plasma, the real-time QuantiTect ${ }^{\circ}$ PCR assay was used on plasma taken eight weeks after infection from nine infected and nine naive jirds. No Mf could be found at this time confirming a pre-patent status. Patent B. malayi infections in jirds can usually be detected 75-110 days after infection [27]. All infected jirds were confirmed to have adult worms ( median $=40$, range $=9-76)$ when the animals were necropsied. The B. malayi HhaI PCR assay using $10 \mu$ reaction volume showed a positive signal in all infected jirds 8 weeks post infection, but was negative in plasma samples from uninfected jirds (Table 1). Using only $2 \mu \mathrm{l}$ of template DNA with the QuantiTect master mix, there was no detection of the HhaI tandem DNA repeat. The results confirmed the sensitivity of the HhaI PCR when using an increased volume of template DNA in pre-patent, Mf-negative samples.

Plasma samples of European blood donors, 19 samples with different parasite infections and 10 plasma samples from $W$. bancrofti infected patients were tested with the HhaI PCR 2 and $10 \mu \mathrm{l}$ assays. These controls were all negative, confirming the specificity of the HhaI PCR primers and minor groove binding hybridization probe as previously reported [19].

The PCR was further validated using samples from 30 Mf-positive individuals from Central Sulawesi and 9 elephantiasis patients, one of whom was Mf-positive. The HhaI gene was detected in all Mf-positive samples confirming the sensitivity of the PCR in microfilaremic samples (positive controls). Copy numbers of the HhaI gene were positively correlated to the number of $\mathrm{Mf}$ (Spearman's rank correlation, $\mathrm{r}=0.48, P=0.0072$ ). In the elephantiasis group, the $2 \mu \mathrm{l} \mathrm{PCR}$ assay detected HhaI in $78 \%$ of the samples, although only one patient was Mf-positive with $1 \mathrm{Mf} / \mathrm{ml}$ (Table 2). In the $10 \mu \mathrm{l}$ assay, all elephantiasis patient samples were positive for HhaI with a median of 57 copies/ $\mu$ l (range: 5-538; Additional file 4A) compared to Mf-positive samples with a median of 448 copies/ $\mu$ l (range 25-8252; Additional file $4 \mathrm{~B})$. The IgG4 test in LE patients was positive in only $3 / 9$ samples $(27 \%)$. Even though LE patients often lack Mf and are negative for CFA in W. bancrofti infections, it is assumed that LE patients in endemic areas have a constant exposure to incoming larvae (L3), which more strongly stimulate the hosts' immune system, resulting in L3 killing (and thus no infection) at the expense of tissue damage. DNA from these L3 can be detected by the sensitive HhaI PCR.

After validating the sensitivity and specificity of the assay, plasma samples from 229 transmigrants in South Sulawesi and 105 life-long residents (LLR) were measured with the HhaI PCR. All 19 Mf-positive patients were positive for HhaI and IgG4 dipstick (Additional file 1).

Defining Mf-positive (Central Sulawesi and transmigrants) and LE samples as having or having had an active infection, the Mf numbers significantly correlated with

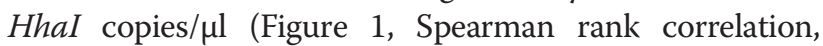
$r=0.52, P<0.001)$. The linear regression line from the correlation crossed the Y-axis at $47.31 \mathrm{HhaI}$ copies/ $\mu \mathrm{l}$ $(\mathrm{SD}= \pm 1.43)$ (Figure 1). The threshold of active infections

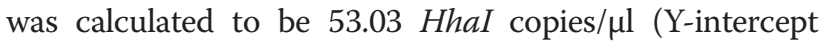
plus 4XSD) [28]. Transmigrant samples with HhaI copy numbers below the threshold were assumed to have DNA from L3 that were killed, but no active infection.

Using a ROC curve we were able to calculate possible thresholds with the coordinates of the curve (Figure 2). The variable $H$ haI copies/ $\mu \mathrm{l}$ has at least one tie (at 53.5 HhaI copies/ $\mu$ l) between the sensitivity (true positive rate, Mf positive and infected) and the 1-specificity (false positive group, Mf-negative, uninfected/exposed). Therefore a threshold (cutoff) of 53.5 HhaI copies/ $\mu$ l was found to best discriminate between real infections and uninfected/exposed individuals based on PCR results.

Table 1 Hhal detection in plasma from pre-patent jirds (56 days post infection) $2 \mu \mathrm{l}$ and $10 \mu \mathrm{l}$ sample DNA volume

\begin{tabular}{|c|c|c|c|}
\hline Animal group & $\begin{array}{c}\text { Hhal positives } \\
(2 \mu \text { l sample volume) }\end{array}$ & $\begin{array}{c}\text { Hhal positives } \\
\text { (10 } \mu \text { l sample volume) }\end{array}$ & Adult worm recovery ${ }^{a}$ \\
\hline Infected jirds ( $9 / 9$ patent) & $0 / 9$ & $9 / 9$ & $40(9-76)$ \\
\hline Uninfected jirds & $0 / 9$ & $0 / 9$ & 0 \\
\hline
\end{tabular}

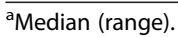


Table 2 Validation of the Hhal real-time PCR using positive control patients from Central Sulawesi, Indonesia

\begin{tabular}{|c|c|c|c|c|c|c|}
\hline Infection status & $\begin{array}{c}\text { PCR positive } \\
(2 \mu \text { sample volume })\end{array}$ & $\%$ & $\begin{array}{c}\text { PCR positive } \\
(10 \mu \mathrm{l} \text { sample volume) }\end{array}$ & $\%$ & $\begin{array}{l}\text { IgG4 dipstick } \\
\text { positive }\end{array}$ & $\%$ \\
\hline Mf positive patients $(n=30)$ & $30 / 30$ & 100 & $30 / 30$ & 100 & $30 / 30$ & 100 \\
\hline \multicolumn{7}{|l|}{ Elephantiasis patients } \\
\hline (Mf-positive $n=1$, Mf-negative $n=8$ ) & $7 / 9$ & 78 & $9 / 9$ & 100 & $3 / 9$ & 27 \\
\hline
\end{tabular}

ROC-curve analysis confirmed that the threshold determined with the correlation and regression line had good discriminatory power (AUC $=0.854 ; \mathrm{P}<0.001$ ) (Figure 2). Using a cutoff of 53 copies/ $\mu \mathrm{l}, 74.1 \%$ true-positive and $20 \%$ false-positive rates were calculated by ROC-curve analysis (Figure 2, Table 3). Based on these analyses, we set 53 HhaI copies as the cutoff to differentiate patients with an active infection (persons infected with adult worms) from those who only had been exposed to infective larvae.

A more detailed analysis was performed by quantifying the HhaI gene in the transmigrant samples, sorting them by time of residence and using the cutoff to assign infection status. A positive HhaI qPCR result could indicate exposure to larvae (L3) $(<53$ HhaI copies/ $\mu$ l, below cutoff) or infection with adult worms that may or may not release Mf ( $>53$ HhaI copies/ $\mu$ l, above cutoff). In the transmigrants present for less than one month all individuals had $<53$ HhaI copies/ $\mu$ l (Table 4 , Figure 3 ). In the 2-4 months and 3 years group, $24-25 \%$ had HhaI levels above the cutoff, whereas IgG4 results, which detect host antibodies to adult worms and Mf, were first seen after 3 years residence (7\%). After living for 4 years in the endemic area, $69 \%$ of the transmigrants had HhaI copy numbers above the cutoff, but only $12 \%$ were detected by the IgG4 antibody test. After 4 years residence, Hhal copy numbers in $62 \%$ of the transmigrants were

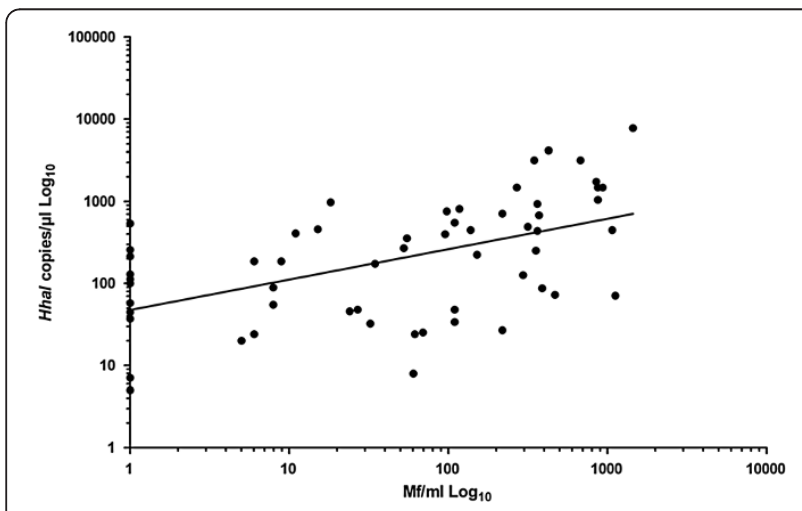

Figure 1 Determination of a threshold for infection. Mf loads from Mf-positive and LE patients were correlated to Hhal copies/ $\mu$ l $(n=58)$. Linear regression was performed to calculate the $Y$-intercept and standard deviation of the line. The threshold was defined as: Y-intercept (47.31) + 4XSD (1.43). Spearman Rank correlation resulted in $r=0.52$ with $P<0.001$ (PASW 18.0 software package). similar to those of LLR. The IgG4 test results in $42 \%$ of the transmigrants were similar to those of LLR after 5 years of residence. Dividing the transmigrant population into two groups (residence $<3$ and $>3$ years) there was a significant trend for higher HhaI copy numbers in the group living more than 3 years in the endemic area (CochranArmitage test for trend $P<0.001$ ). Additionally the number of individuals showing PCR results above the cutoff (53 HhaI copies) was significantly increased in the 4-6 year group ( $\mathrm{P}<0.001$ Fisher's exact test).

In summary these results indicate that in Mf-negative individuals the PCR has a higher rate of detection than IgG4 serology in transmigrants. After 3 or more years of residence in the endemic area, the copy numbers for HhaI and the respective rate of active infection increases. In all groups we found samples with low HhaI copy numbers ( $<53$ copies). We conclude that, in most cases, these individuals have been exposed to infective larvae but have no active worm infection.

\section{Discussion}

Filariasis experts have requested the development of tests that can detect infection in individuals with ultralow Mf densities or cryptic infections [29]. In recent

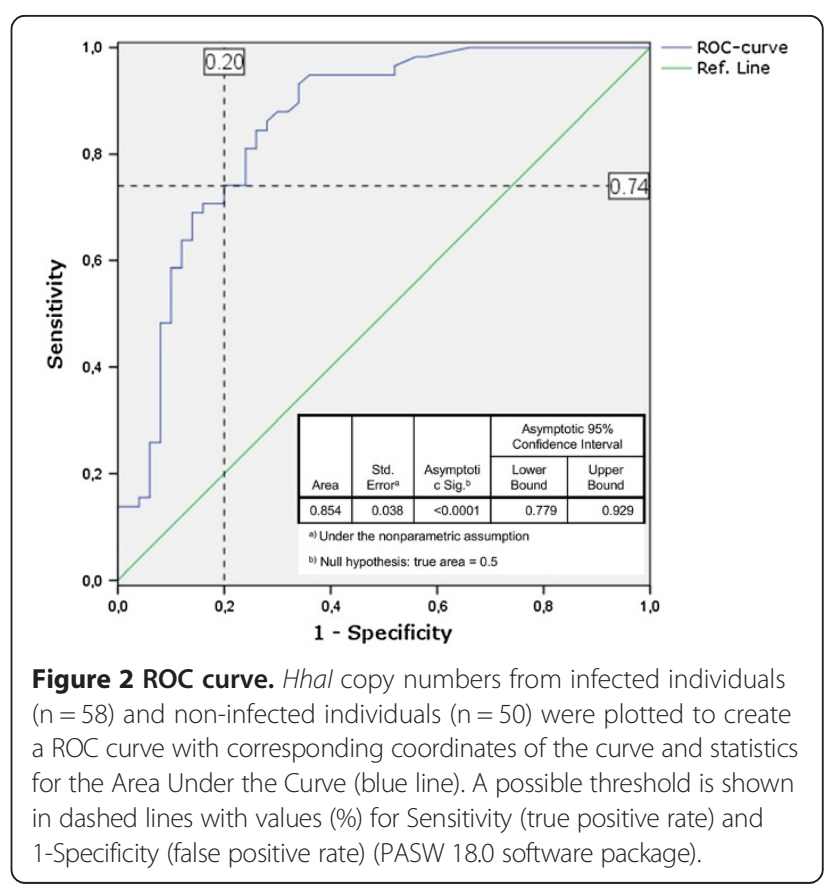


Table 3 Coordinates of ROC curve

\section{Positive if greater Sensitivity}

than or equal To

1.00

1.50

2.50

3.50

4.50

5.50

6.50

7.50

8.50

9.50

12.00

14.50

15.50

16.50

17.50

18.50

19.50

22.00

24.50

25.50

26.50

29.50

32.50

33.50

35.50

39.50

43.50

45.50

47.00

50.00

53.50

56.00

58.50

61.00

66.00

70.50

72.00

80.00

88.00

90.00

95.50

106.00

119.00 (True positive)

1-Specificity
(False positive)

$1.000 \quad 1.000$

1.000

1.000

1.000

1.000

.983

.983

.966

.948

.948

.948

.948

.948

.948

.948

.948

.948

.931

.897

.879

.879

.862

.845

.845

.828

.810

.810

.793

.776

.741

.741

.724

.707

.707

.707

.690

.690

.672

.655

.638

.638

.621

.603
Table 3 Coordinates of ROC curve (Continued)

\begin{tabular}{|c|c|c|}
\hline 126.50 & .586 & .120 \\
\hline 128.00 & .586 & .100 \\
\hline 150.50 & .569 & .100 \\
\hline 179.50 & .552 & .100 \\
\hline 200.50 & .517 & .100 \\
\hline 220.00 & .500 & .100 \\
\hline 226.50 & .483 & .100 \\
\hline 239.00 & .483 & .080 \\
\hline 255.00 & .466 & .080 \\
\hline 264.50 & .448 & .080 \\
\hline 313.50 & .431 & .080 \\
\hline 378.00 & .414 & .080 \\
\hline 404.50 & .397 & .080 \\
\hline 425.50 & .379 & .080 \\
\hline 443.50 & .362 & .080 \\
\hline 448.00 & .345 & .080 \\
\hline 452.00 & .328 & .080 \\
\hline 472.50 & .310 & .080 \\
\hline 514.50 & .293 & .080 \\
\hline 543.00 & .276 & .080 \\
\hline 579.50 & .259 & .080 \\
\hline 644.50 & .259 & .060 \\
\hline 689.50 & .241 & .060 \\
\hline 734.00 & .224 & .060 \\
\hline 787.50 & .207 & .060 \\
\hline 867.50 & .190 & .060 \\
\hline 950.00 & .172 & .060 \\
\hline 980.50 & .155 & .060 \\
\hline 1021.00 & .155 & .040 \\
\hline 1092.50 & .138 & .040 \\
\hline 1303.50 & .138 & .020 \\
\hline 1479.50 & .138 & .000 \\
\hline 1487.50 & .121 & .000 \\
\hline 1494.00 & .103 & .000 \\
\hline 1611.00 & .086 & .000 \\
\hline 2439.50 & .069 & .000 \\
\hline 3173.00 & .052 & .000 \\
\hline 3665.00 & .034 & .000 \\
\hline 5964.00 & .017 & .000 \\
\hline 7792.00 & .000 & .000 \\
\hline
\end{tabular}

Bold text indicates the cut-off that is used to differentiate active infection from exposure.

years, improved diagnostic methods became available for brugian infections, but were mainly based on $\mathrm{Mf}$ positive samples. To meet the request for tests that 
Table 4 Detection of B. malayi Hhal in transmigrants and life-long residents in South Sulawesi, Indonesia

\begin{tabular}{|c|c|c|c|c|c|c|}
\hline $\begin{array}{l}\text { Length of } \\
\text { residence }\end{array}$ & $\begin{array}{c}\text { Analyzed } \\
\text { individuals }\end{array}$ & $\begin{array}{l}\text { Children/ } \\
\text { Adults }^{\mathrm{a}}\end{array}$ & Mf prevalence & $\begin{array}{c}\text { Hhal PCR prevalence } \\
>53 \text { copies }(\%)\end{array}$ & $\begin{array}{l}\text { Hhal PCR prevalence } \\
<53 \text { copies }(\%)^{\mathbf{b}}\end{array}$ & $\begin{array}{c}\text { IgG4 BmR1 } \\
\text { prevalence (\%) }\end{array}$ \\
\hline$\leq 1$ month & 15 & $1 / 14$ & $--^{c}$ & $0 / 15(0)$ & $12 / 15(80)$ & $0 / 15(0)$ \\
\hline 2-4 months & 33 & $10 / 23$ & $--^{c}$ & $8 / 33(24)$ & $17 / 33(52)$ & $0 / 33(0)$ \\
\hline 3 years & 67 & $34 / 33$ & $0^{d}$ & $17 / 67(25)$ & $41 / 67(61)$ & $5 / 67(7)$ \\
\hline 4 years & 52 & $19 / 33$ & 0 & $36 / 52(69)$ & $14 / 52(27)$ & $6 / 52(12)$ \\
\hline $5-6$ years & 60 & $28 / 32$ & 5 & $36 / 60(60)$ & $14 / 60(23)$ & $25 / 60(42)$ \\
\hline LLR & 105 & $71 / 34$ & 14 & $65 / 105(62)$ & 30/105 (29) & $42 / 105(40)$ \\
\hline Total & 334 & $165 / 169$ & 19 & & & \\
\hline
\end{tabular}

${ }^{\mathrm{a} C h i l d r e n} \leq 15$ years, adults 16 years + .

${ }^{\mathrm{b}}$ All samples $<2 \mathrm{Hhal}$ copies/ $\mu \mathrm{l}$ were considered PCR negative (detection limit), all samples $<53 \mathrm{Hhal}$ copies/ $\mu \mathrm{l}$ were considered as not infected.

${ }^{c}$ For logistic reasons blood was collected during daytime in 2 villages, therefore Mf counts are absent.

${ }^{\mathrm{d}} \mathrm{Mf}$ prevalence in the 3 -year residents could be determined in 20 individuals only.

detect infections when Mf are no longer detected, e.g. due to successful MDA, we modified the HhaI QuantiTect ${ }^{\circ}$ PCR, previously developed by Rao et al. [19] by using a novel mastermix setup that allowed us to increase the sample DNA volume to $50 \%$ of the reaction volume. We validated the new assay with a $B$. malayi animal model and a unique sample set from an Indonesian transmigrant population with a known history of time spent in an endemic area. In our experiments, the optimized qPCR assay was sensitive at detecting Brugia DNA in pre-patent amicrofilaremic animals, Mf-positive patients from Central Sulawesi and in a large set of amicrofilaremic patients from South Sulawesi. These results are novel to previous studies, as we were especially focusing on Mf-negative samples with a pre-patent, latent or cryptic/occult infection. These groups are often seen in the related $W$. bancrofti infections for which a specific antigen test is available.

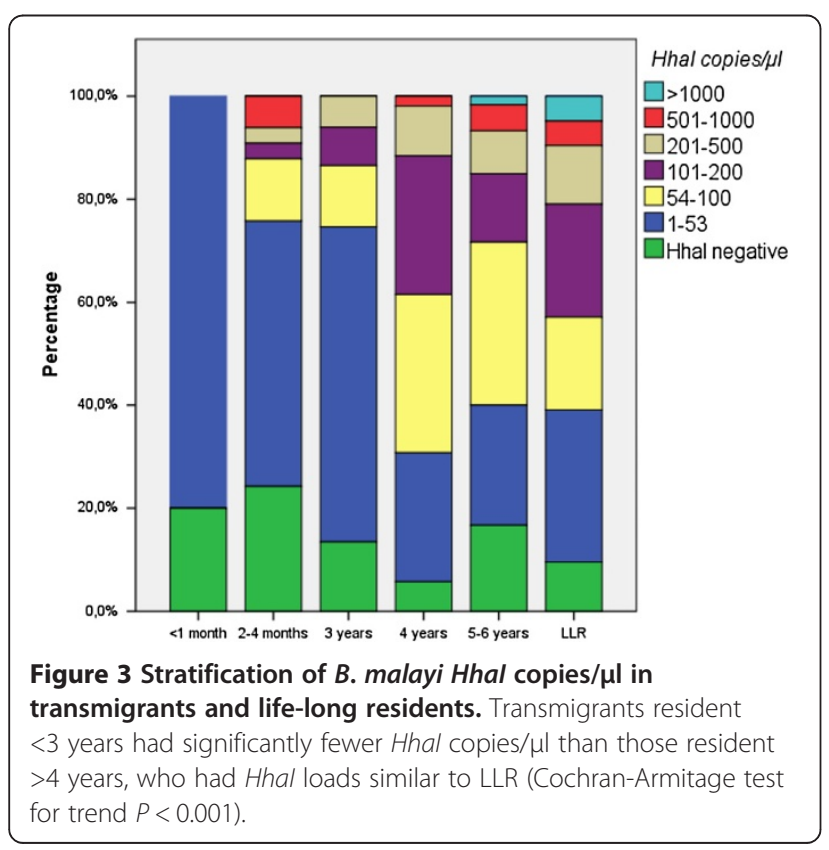

The 320-bp HhaI tandem repeat sequence of $B$. malayi has been used as a target for $B$. malayi PCR assays for many years $[19,20]$. Rao et al. found that detection of the Brugia HhaI repeat was as sensitive as microscopic detection of Mf analyzing mainly Mf-positive samples from a highly endemic area [19]. Additionally, the real-time PCR assay showed higher sensitivity compared to conventional PCR and TaqMan PCR assays and detected DNA of nocturnally periodic $B$. malayi in day blood samples. This represented a significant improvement over previously available diagnostic methods in brugian filariasis. The HhaI repeat is specific for brugian filariasis and is not detected in W. bancrofti infections, which is also endemic in South East Asia. The PCR does not crossreact with other common worm infections, further underscoring the specificity of the assay as seen in our results and by Rao et al. [19]. We were able to confirm the sensitivity of the assay in different states of infection using samples from $B$. malayi infected but pre-patent jirds, from uninfected jirds and samples from patients with LE who were mostly amicrofilaremic and possibly without adult worm infection (assuming similar infection kinetics as with bancroftian LE).

The question arose whether the qPCR was able to detect circulating worm DNA in plasma without circulating Mf, a case that would be seen in pre-patent infections and chronic pathology such as LE. From our results we concluded that this was the case, and it is also in concordance with other worm infections, e.g. schistosomiasis in which a positive PCR result was seen while worms were establishing liver infection, i.e. in pre-patency [30].

LF is mainly diagnosed by direct microscopic demonstration of Mf in peripheral night blood of infected people. However, this method does not detect amicrofilaremic individuals with adult worm infection, i.e., latent or prepatent infections, who are still at risk of developing pathology. For $W$. bancrofti infections, assessment of antigenemia using the $\mathrm{ICT}^{\circ}$ or $\mathrm{TropBio}^{\circ}$ ELISA test kits is available to detect infections in amicrofilaremic individuals 
and offers the convenience of "any-time-of-day testing" [31]. It could be shown in bancroftian filariasis that approximately twice as many individuals are CFA + than are microfilaremic [11]. Ultrasonography (USG), an additional tool for W. bancrofti diagnosis, can be used to detect adult filarial worms by their "filarial dance sign" [32]. In brugian filariasis, accounting for $10 \%$ of the 120 million worldwide LF infections, no antigen test is available and attempts to reliably detect adult filariae with USG examinations have failed [33] or did not allow reliable, frequent detection [12].

To get a more detailed view of the sensitivity of the HhaI assay, particularly in amicrofilaremic infections, we analyzed a large number of individuals that had moved from a non-endemic area to a $B$. malayi endemic area. In the group of individuals who were in the endemic area less than four years, our results showed a very high HhaI positive rate (up to $80 \%$ ), whereas none of these individuals were IgG4 positive. The high rate of detection in this group of transmigrants was unexpected. We concluded that the positive PCR results were due to exposure to infective larvae, not to active infections with adult worms. As the HhaI copy numbers were very low in these groups we defined a threshold which could discriminate between exposed and infected individuals based on real-time PCR results.

For monitoring Brugia infections using day samples we used ROC-curve analysis to set the threshold associated with active infection to $>53 \mathrm{HhaI}$ copies/ $\mu \mathrm{l}$ in a reaction using $10 \mu \mathrm{l}$ of plasma DNA and the QuantiTect ${ }^{\circ}$ Virus NR Kit. This analysis predicted a $74.1 \%$ true-positive result for detecting an active infection in Mf-negative people. To our knowledge, this is the first time that results of qPCR in B. malayi infections have been used to discriminate between active adult worm infections and exposure to infective L3 larvae. The threshold found in our results may require a trial at other endemic sites, or a multicenter trial, to confirm the current cutoff. Comparing LLR to the transmigrants present in the endemic area for 6 years, the percent of Mf-positives are 13\% and $12 \%$, respectively, showing that over time, the infections detected in the transmigrant population are not false alarms. It is also possible to set a higher threshold based on the coordinates of the ROC curve. For example a threshold set at 100 HhaI copies for active infections, with a decreased true positive rate $(62 \%)$ and respectively decreased false positive rate (12\%), would reflect more or less the results of the IgG4 antibody test. If the threshold is set at 53 HhaI copies, the likelihood to detect exposed but not yet infected individuals is higher. The results show that PCR cannot replace individual diagnostics for the determination of infection status, but could help mapping endemic areas which is important for monitoring mass drug administration (MDA) programs $[9,18,19]$.
The discrepancy of PCR and IgG4 results in the first years of living in an endemic area may be due to the PCR sensitivity for incoming larvae, most of which will not develop into an active infection. Edeson et al. showed in animal experiments with B. malayi that only $13 \%$ of over 400 injected larvae develop into adult worms [34]. The $87 \%$ of the larvae that are killed would then be detected by PCR and do not reflect active infection. The parasite burden in the first years after transmigration is probably not high enough to produce detectable IgG4 antibodies, whereas PCR is able to detect parasite DNA in individuals that are exposed to infective larvae. Notably there were individuals with high HhaI copies/ $\mu$ l who were IgG4 negative. Based on serology they would have been diagnosed as Brugia negative even though it is likely they have prepatent or at one time had active infections. Conversely, however, there were also 19 IgG4 positive individuals that were diagnosed as PCR-negative, indicating previous exposure to filarial worms or larvae but no current active infection. Regarding the population dynamics of $B$. malayi our qPCR results showed that HhaI copies/ $\mu$ increase with length of time in the area, and indicate the development of active infections.

Introduction of the CFA test for W. bancrofti infections showed that $50 \%$ of the population in an endemic area had a latent infection. In our study with a highly sensitive and specific qPCR targeting the B. malayi HhaI repeat sequence we observed a similar level of latent infections with B. malayi infections that, importantly, would not be detected by IgG4 serology or microscopy. Compared to an antigen test used for $W$. bancrofti infection the qPCR is more expensive, but there is currently no other method available for detecting $B$. malayi infections in Mf-negative persons with latent infections.

\section{Conclusions}

The modified real-time PCR for the HhaI repeat sequence, which is highly sensitive and specific for $B$. malayi, may become an effective method for monitoring $B$. malayi control programs. Due to possible development of severe LF pathology such as lymphedema, the ability to determine the status of infection, especially in amicrofilaremic patients, as early as possible could lead to prevention of disease progression in individuals of endemic areas. Additionally, identifying possible recrudescence after MDA early could help local health services intervene and prevent wide-spread recrudescence that might otherwise require several years of MDA to be implemented. In the absence of an antigen test for brugian infections the optimized B. malayi HhaI PCR can be used to identify infected Mf-negative individuals and should also be useful for assessing the success of MDA in the framework of the Global Programme to Eliminate Lymphatic Filariasis. 


\section{Additional files}

Additional file 1: Flow Chart comparing the sensitivity of Hhal PCR
and IgG4 BmR1 dipstick test.
Additional file 2: DNA extraction and real-time PCRs.
Additional file 3: Detection limit of the B. malayi Hhal real-time
PCR in the $2 \mu \mathrm{l}$ and $10 \mu \mathrm{l}$ assays.
Additional file 4: Validation of the Hhal PCR with samples from
B. malayi LE and Mf positive volunteer DNA samples.

Competing interests

The authors declare that they have no competing interests.

\section{Authors' contributions}

AA participated in the study design, conducted laboratory tests and statistics, interpreted laboratory results, wrote and edited the manuscript. ES participated in organization and design of the study and provided patient samples. SW participated in organization and design of the study and provided patient samples. MY participated in organization and design of the study and provided patient samples. RMM conducted animal experiments and provided animal samples. UKS participated in statistical analysis of the data. KP participated in the study design, conducted laboratory tests, edited and submitted the manuscript. $\mathrm{AH}$ conceived the study, and wrote and edited the manuscript. All authors read and approved the final version of the manuscript.

\section{Acknowledgements}

This work was supported by the European Union, European Commission, INCO programme [contract No. 32321, FP6-INCO]; the Netherlands Foundation for the Advancement of Tropical Research [WOTRO, W93-266]; and intramural funding from University Hospital of Bonn [BONFOR to AA]. We thank Dr. CP Ramachandran, GPELF, for his kind discussion about GPELF and brugian filariasis.

\section{Author details}

IInstitute of Medical Microbiology, Immunology and Parasitology, University Hospital of Bonn, Sigmund-Freud-Str. 25, D-53105 Bonn, Germany.

${ }^{2}$ Department of Parasitology, Leiden University Medical Center, P.O Box 9600, 2300, RC Leiden, The Netherlands. ${ }^{3}$ Parasitology Department, Medical Faculty, Hasanuddin University, Jl. Perintis Kemerdekaan 10 Tamalanrea, Makassar 90245, Indonesia. ${ }^{4}$ Institute for Immunology \& Infection Research, University of Edinburgh, Ashworth Laboratories, Edinburgh EH9 3JT, UK. ${ }^{5}$ Institute for Medical Biometry, Informatics, and Epidemiology, University Hospital of Bonn, Sigmund-Freud-Str. 25, D-53105 Bonn, Germany.

Received: 12 September 2013 Accepted: 12 March 2014

Published: 31 March 2014

\section{References}

1. WHO: Global programme to eliminate lymphatic filariasis: progress report for 2012. Wkly Epidemiol Rec 2012, 88:389-399.

2. WHO: Lymphatic Filariasis: reasons for hope. In. Edited by Diseases DCT. Geneva: World Health Organization; 1997:20.

3. Sudomo M, Chayabejara S, Duong S, Hernandez L, Wu WP, Bergquist R: Elimination of lymphatic filariasis in Southeast Asia. Adv Parasitol 2010, 72:205-233.

4. WHO: World Health Organization. Global programme to eliminate lymphatic filariasis: progress report on mass drug administration in 2010. Wkly Epidemiol Rec 2010, 86:377-388.

5. WHO: Progress report 2000-2009 and strategic plan 2010-2020 of the global programme to eliminate lymphatic filariasis: halfway towards eliminating lymphatic filariasis. In. Geneva: World Health Organization; 2010.

6. Mand S, Marfo-Debrekyei Y, Dittrich M, Fischer K, Adjei O, Hoerauf A: Animated documentation of the filaria dance sign (FDS) in bancroftian filariasis. Filaria J 2003, 2:3.

7. Department of Health, Republic of Indonesia: Guideline for determination of the endemic area of filariasis (Pedoman penyakit kaki gajah). Jakarta: Direktorat Jenderal PPM \& PL; 2002.

8. McCarthy J (Ed): Diagnosis of lymphatic filariasis infection. United Kingdom: Imperial College Press; 2000.
9. Simonsen PE, Dunyo SK: Comparative evaluation of three new tools for diagnosis of bancroftian filariasis based on detection of specific circulating antigens. Trans R Soc Trop Med Hyg 1999, 93:278-282.

10. Weil GJ, Lammie PJ, Weiss N: The ICT Filariasis Test: a rapid-format antigen test for diagnosis of bancroftian filariasis. Parasitol Today 1997, 13:401-404.

11. Turner P, Copeman B, Gerisi D, Speare R: A comparison of the Og4C3 antigen capture ELISA, the Knott test, an IgG4 assay and clinical signs, in the diagnosis of Bancroftian filariasis. Trop Med Parasitol 1993, 44:45-48.

12. Mand S, Supali T, Djuardi J, Kar S, Ravindran B, Hoerauf A: Detection of adult Brugia malayi filariae by ultrasonography in humans in India and Indonesia. Trop Med Int Health 2006, 11:1375-1381.

13. Noordin R, Anuar AK, Ariff RH, Zurainee MN, A'Shikin AN, Fadzillah A, Maimunah A, Haq JA: Use of antifilarial IgG4-ELISA to detect Brugia malayi infection in an endemic area of Malaysia. Trop Med Int Health 1998, 3:184-188.

14. Noordin R, Lim BH, Khairul Anuar A, Shenoy RK, Kumaraswami V, Lokman Hakim S, Chotechuang P, Kanjanopas K, Ramachandran CP: A recombinant antigen-based IgG4 ELISA for the specific and sensitive detection of Brugia malayi infection. Trans R Soc Trop Med Hyg 2001, 95:280-284.

15. Rahmah N, Taniawati S, Shenoy RK, Lim BH, Kumaraswami V, Anuar AK, Hakim SL, Hayati MI, Chan BT, Suharni M, Ramachandran CP: Specificity and sensitivity of a rapid dipstick test (Brugia Rapid) in the detection of Brugia malayi infection. Trans R Soc Trop Med Hyg 2001, 95:601-604.

16. Weil GJ, Curtis KC, Fischer PU, Won KY, Lammie PJ, Joseph H, Melrose WD, Brattig NW: A multicenter evaluation of a new antibody test kit for lymphatic filariasis employing recombinant Brugia malayi antigen Bm-14. Acta Trop 2011, 120(Suppl 1):19-22.

17. Bell AS, Ranford-Cartwright LC: Real-time quantitative PCR in parasitology. Trends Parasitol 2002, 18:337-342.

18. Fink DL, Fahle GA, Fischer S, Fedorko DF, Nutman TB: Toward molecular parasitologic diagnosis: enhanced diagnostic sensitivity for filarial infections in mobile populations. J Clin Microbiol 2010, 49:42-47.

19. Rao RU, Weil GJ, Fischer K, Supali T, Fischer P: Detection of Brugia parasite DNA in human blood by real-time PCR. J Clin Microbiol 2006, 44:3887-3893.

20. Pilotte N, Torres M, Tomaino FR, Laney SJ, Williams SA: A TaqMan-based multiplex real-time PCR assay for the simultaneous detection of Wuchereria bancrofti and Brugia malayi. Mol Biochem Parasitol 2013, 189:33-37.

21. Noordin R, Wahyuni S, Mangali A, Huat LB, Yazdanbakhsh M, Sartono E: Comparison of IgG4 assays using whole parasite extract and BmR1 recombinant antigen in determining antibody prevalence in brugian filariasis. Filaria J 2004, 3:8

22. Terhell AJ, Haarbrink M, Abadi K, Syafruddin, Maizels RM, Yazdanbakhsh M, Sartono E, Syafruddin, Maizels RM, Yazdanbakhsh M, Sartono E: Adults acquire filarial infection more rapidly than children: a study in Indonesian transmigrants. Parasitology 2001, 122:633-640.

23. Partono F, Oemijati S, Hudojo, Joesoef A, Sajidiman H, Putrali J, Clarke MD, Carney WP, Cross JH: Malayan filariasis in Central Sulawesi (Celebes), Indonesia. Southeast Asian J Trop Med Public Health 1977, 8:452-458,

24. Opsteegh M, Teunis P, Mensink M, Zuchner L, Titilincu A, Langelaar M, van der Giessen J: Evaluation of ELISA test characteristics and estimation of Toxoplasma gondii seroprevalence in Dutch sheep using mixture models. Prev Vet Med 2010, 96:232-240.

25. Opsteegh M, Teunis P, Zuchner L, Koets A, Langelaar M, van der Giessen J: Low predictive value of seroprevalence of Toxoplasma gondii in cattle for detection of parasite DNA. Int J Parasitol 2011, 41:343-354.

26. Greiner M, Pfeiffer D, Smith RD: Principles and practical application of the receiver-operating characteristic analysis for diagnostic tests. Prev Vet Med 2000, 45:23-41.

27. Ash $L R$, Riley JM: Development of subperiodic Brugia malayi in the jird, Meriones unguiculatus, with notes on infections in other rodents. J Parasitol 1970, 56:969-973.

28. Rahmah N, Ashikin AN, Anuar AK, Ariff RH, Abdullah B, Chan GT, Williams SA: PCR-ELISA for the detection of Brugia malayi infection using finger-prick blood. Trans R Soc Trop Med Hyg 1998, 92:404-406.

29. Addiss D: The 6th Meeting of the Global Alliance to Eliminate Lymphatic Filariasis: a half-time review of lymphatic filariasis elimination and its integration with the control of other neglected tropical diseases. Parasit Vectors 2010, 3:100. 
30. Wichmann D, Panning M, Quack T, Kramme S, Burchard GD, Grevelding C, Drosten C: Diagnosing schistosomiasis by detection of cell-free parasite DNA in human plasma. PLoS Negl Trop Dis 2009, 3:e422.

31. Lammie PJ: Research direclty linked with GPELF activities (operational research): essential tools-diagnostics. Am J Trop Med Hyg 2004, 71:3-6.

32. Amaral F, Dreyer G, Figueredo-Silva J, Noroes J, Cavalcanti A, Samico SC, Santos A, Coutinho A: Live adult worms detected by ultrasonography in human Bancroftian filariasis. Am J Trop Med Hyg 1994, 50:753-757.

33. Shenoy RK, John A, Hameed S, Suma TK, Kumaraswami V: Apparent failure of ultrasonography to detect adult worms of Brugia malayi. Ann Trop Med Parasitol 2000, 94:77-82

34. Edeson JF, Buckley JJ: Studies on filariasis in Malaya: on the migration and rate of growth of Wuchereria malayi in experimentally infected cats. Ann Trop Med Parasitol 1959, 53:113-119.

doi:10.1186/1756-3305-7-146

Cite this article as: Albers et al:: Real-time PCR detection of the Hhal

tandem DNA repeat in pre- and post-patent Brugia malayi infections: a study in Indonesian transmigrants. Parasites \& Vectors 2014 7:146.

\section{Submit your next manuscript to BioMed Central and take full advantage of:}

- Convenient online submission

- Thorough peer review

- No space constraints or color figure charges

- Immediate publication on acceptance

- Inclusion in PubMed, CAS, Scopus and Google Scholar

- Research which is freely available for redistribution 